\title{
An Anthropological Perspective on Near-Death-Like Experiences in Three Men's Pregnancy-Related Spiritual Crises
}

\author{
Gregg Lahood, Dip. Psych., Ph.D. (cand.) \\ Massey University, Auckland, New Zealand
}

\begin{abstract}
In this article I bring a transpersonal perinatal anthropological perspective to the study of three fathers' near-death-like experiences. I compare Kenneth Ring's descriptions of prototypical near-death experiences (NDEs) with the "spiritual emergencies" of these three New Zealand men during their partners' pregnancies. Their experiences show significant similarities to the classic NDE pattern outlined by Ring (1989). Moreover, these NDE-like experiences appear to unfold in a perinatal sequence as described by Stanislav Grof (1985) and Christopher Bache (2000), adding weight to the notion that a "deep structure" lies behind shamanic initiations, NDEs, and unidentified flying object (UFO) encounters (Ring, 1989). I explore these seemingly anomalous male birth/death/rebirth experiences and draw some parallels with what some Western researchers have called "the shamanic crisis," and I compare their stories with the symbolic reproductive maneuvers of shaman midwives.
\end{abstract}

KEY WORDS: birth; near-death experience; fatherhood; midwifery; perinatal matrices; shamanism.

White man got no dreaming, Him go 'nother way. White man, him go different, Him got road belong himself.

Stanner, 1956, p. 51

Gregg Lahood is a Ph.D. candidate in Transpersonal Anthropology at Massey University in Auckland, New Zealand. Reprint requests should be addressed to Mr. Lahood at the School of Social and Cultural Studies, Massey University, Albany, Auckland, New Zealand; email: lahood@ihug.co.nz. 
Women's "maternity cults," female shamanistic midwifery, "male midwifery," and the couvade syndrome of male sympathetic pregnancy behavior and rituals have not been studied comprehensively as transpersonal events in anthropology, nor have these research topics been related to the study of near-death experiences (NDEs). This lack is due in part to outdated research epochs, the gender inequalities that beset early anthropology, and in part to the political imperatives or fashions driving research priorities. Early anthropology was exclusively a male endeavor, and men were not welcomed in female birthing sites and women's birth magic and shamanism remained largely a secret. Western medical and political colonization also severely impacted traditional birth rituals (Kitzinger, 1982; Laderman, 1983), further marginalizing the nature of their meaning and magic.

With the rise of the women's movement in the 1970s, birthing became a central concern for feminist researchers, although understandably most feminist anthropologists have paid scant attention to male birthing rites and reproductive magic. Like their male anthropological forebears, they have produced a similar set of gender biases, among them the erroneous belief that fathers have little or nothing to do with childbirth in nonWestern cultures (Bates and Turner, 2003; Heggenhougen, 1980; Lahood, 2006; Priya, 1992).

It is interesting to note that according to Kris Heggenhougen, in many indigenous cultures men are very busy with definitive symbolic performances, "believed to bear directly on the outcome of the birth of his child" (1980, pp. 21-22), which have great social and psychological significance. Husbands diligent in their performance are seen to be integral participants in birthing, as their suffering symbolically relieves the woman's fear in proportion to which they can perform the suffering (Heggenhougen, 1980).

This study concerns the pregnancy-related near-death-like experiences of three contemporary New Zealand males from a transpersonal anthropological perspective (Laughlin, 1990, 1994). However, given anthropologists' conceptual struggle to find a useful vantage point for the viewing of this material, I will delve into the ethnographic literature concerning spiritual midwifery, symbolic obstetrical maneuvers, and NDEs to construct a paradigm to view these extraordinary events.

\section{Birth and the NDE}

Near-death experiences (NDEs) are reported to have multiple causes among Westerners (Carr, 1993). The cause most pertinent to 
this article would be women's NDEs catalyzed by labor and birthing. Bruce Greyson has on file some 60 to 70 cases of women who have reported NDEs during labor and childbirth (B. Greyson, personal communication, October 4, 2004), and reports of NDEs have surfaced from women who gave birth while under anesthesia (Greyson and Bush, 1992). Kenneth Ring (1989, p. 16), in an article addressing shamanic initiations, included what he called a prototypical shamanistic initiation-type NDE from a birth-giving mother (see also Bache, 2000; Grof, 1998; and Grof and Halifax, 1977).

Various dynamics of the birthing process have been significantly related to NDEs by Stanislav Grof and his colleagues (Grof, 1977, 1985; Grof and Grof, 1980, 1989; Grof and Halifax, 1977) and Christopher Bache (1996, 2000). Grof has comprehensively explored adult recollections of fetal trauma and the overlapping interface of birth, sex, and death in the human unconscious from the perspectives offered through psychotherapy with d-lysergic acid (LSD) and holotropic research (1975, 1985, 1988; Grof and Grof, 1980). From Grof's perspective, the perinatal level of the psyche is close-knit with a dynamic existential/ death constellation and is meaningfully related to women giving birth, with birth trauma, the dynamics of psychospiritual death/rebirth, and with the near-death experience (Grof, 1985).

NDEs then have been linked to birthing, generally from the birthing woman's perspective, which of course is not at all surprising given the dramatic nature of women's birth-giving physiology, the cognitive restructuring that can occur from the ordeal of labor, and, in principle, the encounter with death that birth can represent. Men's experience of birth, on the other hand, tends to be culturally submerged and in many ways rendered invisible. Men are represented as mute "observers" or "witnesses" of women's birth-giving and they are assumed to be somewhat divorced as participants, even though they may be having their own experiences of the impressive biological event. Again, this neglect of a proper analysis of the male experience of a birth event is understandable when weighed against the rigors of the female birthing configuration and the hypermedicalized context of most Western births.

\section{The Spectrum of Death}

In 2001 I initiated transpersonal anthropological research (Laughlin, 1988, 1994; Peters, 1994, 1996; Young and Goulet, 1994) with 
procreative males specifically to find out if transpersonal states of consciousness emerged during what Judith Richman (1982) called their "pregnancy careers," their experiences during the course of their partners' pregnancies, from conception and gestation through labor and birth to the postpartum period. I recorded interviews with 40 fathers and 12 mothers in "conversational anthropology," defined by Adam Kuper as "a conversation ... implicating ethnographers, informants and the ancestral voices they invoke in their conversations" $(1994$, p. 55$)$. Clearly for some men transpersonal phenomena were a portion of their experience, while for others, transpersonal disclosures actually defined their experience of witnessing or participating in a birth. However, almost all fathers I interviewed described a meaningful psychological or emotional encounter with the possibility of death evoked over the duration of the pre- and perinatal episode, that is, around conception, gestation, labor, birth, and the postpartum period.

The interviews I conducted and the anecdotes I collected included a number of associations to death, impermanence, mortality, and ancestry. Of the $\mathbf{4 0}$ fathers I interviewed, several of them described a birth experience as being like a car accident, one man felt as if he were at an ancient funeral service, another at a butchery. Some men described their experiences of being present at the moment of birth as having a similar "energetic" feeling to that of being with a loved one at death. Several men reported out-of-body experiences, dissociation, ordeals, and comparisons to LSD use, as well as comparisons with spiritual states of consciousness and "peak experiences" in which the Western dichotomy between life and death was momentarily erased (Lahood, 2006).

\section{Death Encounters, Vampires, and Shamans}

An example from my fieldwork comes from a 40-year-old American diplomat, Michael, an émigré to New Zealand describing his first night with his child, during which he kept a vigil over his son to make sure that his son did not stop breathing - in other words, to make sure he did not die. He said he was awake most of the night in what he described as an "exhausting 12-hour peak experience" that "wrecked me" and from which he needed to recover. Michael described his experience as follows:

At the time I put this down to jet lag and extreme tiredness or 
just adrenalin but there was something like a semi-out-of-body experience. ... It's like I knew I was still in my body, but getting up on my elbow to look at my son breathing wasn't like I'm doing it now. It was like my consciousness was rising up, not my body. And saying it like that does not satisfy me as it comes out of my mouth... .It's like ... I don't know if you ever read Interview with the Vampire [Rice, 1976]. It might sound like I digress, but there's a passage in there where Lestat, the original vampire in that story, creates ... makes Lewis into a vampire. And there's this process of drawing blood, putting blood back, making him take blood, and that starts a process that lasted through the night of his body dying. In other words, he doesn't need to eat anymore, and the shit he has is the last shit he'll ever have, and he goes into the forest and essentially his old self gets flushed out of him. It's kind of an interesting passage, better than I can recall it, but at the same time his otherworldly body takes over where he's got these extra senses: better sight, better hearing, stuff like that. I'd say my experience was kind of like that. It's kind of a semi-out-of-the-body experience where the body seemed to be dying away.

It is not hard to spot the death-rebirth imagery throughout his narrative. This image of blood-sucking vampirism, transformation, of the "body dying away" as it is replaced by "otherworldly" powers, bears a striking resemblance to classic descriptions of the dismemberment, demonic encounter, and resurrection sequences found in Siberian shamanic initiations. The shaman-to-be, having come close to death, somehow enters a visionary world filled with demons where he or she can have the flesh torn from his or her skeleton, entrails removed, blood drained, and organs replaced with precious stones (Eliade, 1964).

According to Joan Halifax, the neophyte shaman is drawn into his or her career often through an initiatory NDE:

those who have nearly died, through an accident or severe illness, or who have suffered a psychological or spiritual trauma ... the encounter with death and dying and the subsequent experience of rebirth and illumination are the authentic initiation for the shaman. (Halifax, 1979, p. 5)

Halifax has also connected biological birth to shamanism's initiatory NDE: "Although this process frequently takes the form of an inner experience, the symbolism and feelings have many unusual parallels in the experience of actual biological birth" $(1979$, p. 5).

Three fathers in my study appeared to participate in what is called a spiritual emergency (Grof and Grof, 1989) and showed ritual activity and self-initiation behaviors (Bateson, 1972; Peters 1994). These three men described experiences that contained several elements found in prototypical NDEs. Their experiences were potent and life-changing: 
one man joined a Christian charismatic church afterwards, fearing he had been possessed by the devil; another was hospitalized for a time in a psychiatric unit; the third gave up surfing.

I will focus first on two of these experiences, comparing them with what Ring has called prototypic NDEs (1989), paying attention to the elements of shamanic initiation and the UFO encounter which they each appear to approximate. I think it is important to reiterate here that it is an encounter with death or the prospect of death, and certain thematic resonances, certain similarities in structure, symbolism, and pattern that these men experience, rather than the "classic" NDE. Yet this is also what makes them so compelling: that, and their relationship to the birth process. Ring described the archetypical NDE pattern as follows:

This pattern is made up of such elements as (1) a psychological sense of separation from the physical body; (2) a feeling of overwhelming peace and well-being; (3) a sense of movement through a dark but not frightening space, sometimes described as a "tunnel"; (4) the perception of brilliant white or golden light by which one is (5) gradually encompassed and from which one (6) feels a sense of total love and unconditional acceptance; (7) an encounter with a "being of light" or other spiritual entities who (8) may afford the occasion for a panoramic life review following which (if it occurs) one (9) may decide or be told to "return to one's own body," thereby (10) terminating the NDE. Such experiences tend to cohere in a highly meaningful way for the individual, are almost always said to be "hyper-real," (i.e., not like a dream or hallucination), and usually have a profound transformative effect on the survivor. (Ring, 1989, p. 14)

\section{Hyperreal Alterity Scapes}

Ring has claimed that near-death researchers are "virtually unanimous in insisting that these experiences do not and cannot suggest the existence of an afterlife" (1990, p. 204). As Bache has written:

[Ring's] articulation of the parallels between transcendent NDEs and the mystical experiences that emerge in various meditative disciplines demonstrated that nearly dying is but a trigger that catapults persons with some consistency into higher states of consciousness that can also be cultivated through any number of consciousness expanding techniques. (Bache, 2000, p. 110)

Therefore the human encounter with death is a catalyst to transpersonal events, and transpersonal events can be a catalyst to an encounter with death. 
Like these researchers, I believe such encounters and the spirited worlds they disclose are real and not fantasy. They belong to a category of "culture" and "reality" that I think of as "alterity-scapes"-alterity in Michael Taussig's sense of an otherworld, or alter-world, a cosmic landscape associated with a culturally imbedded belief system or disclosed in a transpersonal state (Taussig, 1993); and scape after Arjun Appadurai's list of "global flows" he called ethnoscapes, financescapes, technoscapes, mediascapes, and ideoscapes (Appadurai, 1996, pp. 33-37). Henri Corbin called these mind-worlds the mundus imaginalis, after the Persian alam al mithal (Corbin, 1969, 1976); Terrence McKenna called them "hyper-space" (1982); and Michael Grosso called them "the next environment for the psychosocial evolution of man" (1985). James Hillman (1975) has also argued for the irreducible reality of autochthonic imaginals (Ring, 1989, p. 19).

Anthropologists have long noted the existence of such worlds, albeit from shifting epistemological standpoints. In a report more than 100 years old, Edward Tylor observed that the "land of Torngarsuk" to where a Greenlander's soul travels at death, after descending down a bloody slide for five days, is a place of perpetual summer with "good water, birds, fish and seals and reindeer without end" that are caught without trouble, or are found already cooking in a huge pot (1878, p. 296). This suggests an alterity-scape well meshed to the desires of the locals: it is an afterlife that, when pared down, shrouds the deceased in the best of her or his beloved environment and gives unending warmth, light, nourishment, and leisure, a pattern many cultures ascribe to their heavenly abodes. Tylor, like all of us, was a product of his times, and saw in these systems no truth value for humankind, believing they belonged to what he called the "whole monstrous farrago" of primitive religion (cited in Tambiah, 1990, p. 45).

Times have changed. Contemporary transpersonal anthropologists interested in the field of "waking dreams" make efforts to penetrate the alterity-scape of their host culture, seeing the experience as an essential form of data gathering and research (Laughlin, 1994). My personal experience of two such spiritual landscapes was paradoxical: they "felt" as if they were supra-ordinated or already existing, and so I experienced myself participating in a mind-world that had some sort of pre-existing status; and yet these alterity-scapes seemed also to be in a condition of co-creation with the human participatory imagination (Ferrer, 2002; Heron, 1998; Tarnas, 1991), where I found myself a central creative actor in the cosmic landscape. Corbin referred to this phenomenon as the imaginal world, which does not reduce to 
mechanistic notions of imagination but rather to what Ring called the "cumulative product of imaginative thought itself" (1990, p. 209), unfettered by Cartesian dualism. At death, he wrote, we are liberated into this imaginal realm.

\section{Ancestral Alterity}

I will now present the first of my participant's accounts of an experience with perinatal and near-death overtones. Again, I am not suggesting that these are near-death experiences, but I think they are similar enough to NDEs to be of scholarly and practical import. This story is from a young man in his late 20s of European and Maori descent who had only recently had a child. In the first trimester of his child's fetal existence the man, who lived by a beach, went surfing, as he often did. While surfing he was dumped under the waves and thrown beneath some large rocks and seaweed, where he was dangerously entangled. He told me that he had an acute sense that he might die as he struggled to free himself, and then, at a point of neardrowning, a "vortex" opened in his mind, in which he beheld his "ancestors slowly circling in a golden funnel." These ancestors communicated to him knowledge of how to become a "good man." He then had to tear himself out of his wetsuit to struggle free; he emerged out of the sea naked. This "accident" was extremely meaningful to him and he recounted it in direct relation to his child's conception and her movement toward birth. He felt that his ancestors had orchestrated the moment, and that his frightening spiritual flashpoint had something to do with readying himself and the cosmos for the child's entrance into the world.

Ring observed that there is a "substantial phenomenological overlap" (1990, p. 209) between shamanic initiation and NDEs obvious to students of the field. The story above contains many such initiatory themes. Particularly potent is the shedding of his skin, which has the hallmark of shamanic dismemberment and rebirth. Clearly undergirding the story is a perinatal template: the child leaves the good womb, suffers constriction and struggle culminating in an encounter with death, followed by liberation. This pattern is consistent with Grof's description of perinatal matrices $(1985,1988)$.

This man identified himself as Maori, and Maori culture embeds an ancestor-bearing cosmology of multiple dimensions. Original creation is the template for all creation and is specifically recapitulated at the 
birth of children. Thus a brush with his luminous, all-knowing ancestors in a "golden funnel" may be, in part, contextually mediated by cultural imagination and heritage. James Henare, a Maori elder and orator, described the Maori oral tradition as

a veritable treasure house of genius, wit, condensed wisdom and silent telepathy in the storied souls of our ancestors calling across the ages to their descendants struggling toward the light. (cited in M. Henare, 2001, p. 199)

Students of mythology may also be familiar with the figure of Maui, the trickster demigod of the South Pacific, who in his great "overreaching crime" (Alpers, 1985, p. 70) transformed himself into a "caterpillar that glistens" (Alpers, 1985, p. 70) and entered the vagina of Hine Nui Te Po, a goddess related to death. One version of this story reads:

What you see there is Hine Nui, flashing where the sky meets the earth. Her body is like a woman's, but the pupils of her eyes are greenstone and her hair is kelp. Her mouth is that of a barracuda and in the place where men enter her she has sharp teeth of obsidian and greenstone. (Alpers, 1985, p. 67)

In the story, the little birds accompanying Maui on his quest began to laugh as he wriggled into her in the place "where man enters the world" (Best, 1982, p. 378), and she awakened and crushed him to death in the rocks and kelp of her cosmic vagina (tawhito), heralding the birth of mortality by way of rebirth.

\section{Angels and Aliens: Hyphenating-Alterity}

Another New Zealand father, a medical technician of European descent, told me this rather poignant story. He had recently gone through a painful marital separation after his partner became pregnant by another man. He had moved to a new house with several acres of land with his two children, and a week away from the birth of his ex-wife's new child he had the following experience. One night he awoke to what he thought was the sound of an angel's wings beating above his head and at the end of bed. Startled, he panicked and ran outside naked with only a blanket pulled around his shoulders. He fled across a field in the middle of the night to a small cave his two children had hollowed out in a bank. He told me that he crawled inside the hole and drew himself into a fetal position with the blanket wrapped around him. He said that as the first light of morning began to dawn 
and the birds began to sing, he found it increasingly difficult to breathe, and he believed he was going to suffocate to death: "I thought I was dying." He told me that he could now hear the sound of a fleet of alien spacecraft landing all around the cave area, and he imagined a group of luminous alien beings had come to escort him to another level. As this was occurring he was also running out of breath, and at the moment of his "death" he threw off the blanket and threw himself out of the mouth of the cave into the light of the UFOs. He said he was shocked to realize, in that split second, that the spaceships and aliens were not there, and that he would not die.

This is not, of course, a full-blown NDE, nor yet an alien "abduction" experience. Rather it appears to be an emotional crisis or spiritual emergency induced by his marital loss and its challenging circumstance. Nevertheless, the "deep structure" is telling. Again, anyone familiar with perinatal dynamics would recognize his journey through the four birth matrixes. And indeed several commentators have linked UFO abductions to the sequential unfolding of unconscious perinatal memories (Lawson, 1987; Thompson, 1989). The aftermath appeared to have been even more frightening for this man because he did not understand the experience. He told me he went to his local library and found two possibilities there: either he was psychotic or he was possessed by the devil. He opted for joining a local charismatic church, which offered him an opportunity for exorcism by way of full baptismal immersion, a sense of cosmological safety in Jesus, and the anchor of human community.

The way that both angels and aliens made an appearance in his experience is interesting. He seemed to be caught between two symbol systems and conflicting cultural narratives for describing his event; yet they may not be as disparate as they appear. McKenna (1982) pointed out some of the similar patterns associated with accounts of angels and aliens. Angels, like aliens, are related to hyperreal dimensionality. Angels, like aliens, are hard to get hold of and will not be pinned down like tropical butterflies; yet they inhabit the pathways of belief in so many cultures and populate the sky of so many minds, where they seem hover at the breach between this world and another one. Aliens, like angels, are seen as light beings, harbingers of the Other-real, intermediaries, saviors, bearers of advanced technological wisdom enabling them to slip from one dimension to another with lightening speed: chariots-of-fire techno-angels. According to McKenna (1982), in our technocratic culture angels must come clothed in a technological apotheosis so as to be recognized. 
There is also an ancient Judaic spiritual practice whose mention seems germane to this discussion. It is one that can be seen as an analogue to what we might consider to be more overtly "shamanic" cultures: the Merkabah or chariot practices. According to Roger Walsh, its

practitioners tried to recreate Ezekiel's vision of the divine chariot. After rigorous prayer and discipline, practitioners would experience themselves as ascending through the seven heavens and confronting fearful guardians until they were finally granted a vision of the throne of God. (Walsh, 1995, p. 36)

Concentrative prayers were known as kavvanah, which is ultimately depicted as "a loving intimacy, a clinging to God" (Katz, 1978, p. 35):

The Jewish mystic performs his special mystical devotions and meditations ... in order to purify his soul, i.e. to remove the soul from its entrapment in the material world in order to liberate it for its upward spiritual ascent culminating in devekuth. (Katz, 1978, p. 38)

This pattern is also observed in Mohammed's "Night of the Mirage," where the Prophet was dismembered and purified by angels and flown through hell and up through seven layered heavens into a final selfannihilating encounter with the Throne of Allah (Armstrong, 1991, pp. 138-141; Eliade, 1964, p. 377; Grof and Grof, 1980, p. 41).

While the three father's frameworks in my study varied in surface content, they shared a logical consistency that paralleled the perinatal stencil. They appeared to shape their respective pre-birth crises with language that fit closely with the unfolding perinatal matrices through, in, and around the human psyche. Furthermore, these meaningful pre-birth enactments and ritual-like behaviors included a symbolic, imaginal, or real encounter with death and the use of environmental surfaces symbolic of the womb (for example, under the sea and in a cave) to mediate their crises, which then opened out onto an otherworldly alterity-scape, peopled, respectively, by illumined ancestors and aliens. We can discern in these narratives close parallels to some of Ring's prototypical patterns of NDEs from both the shamanistic and UFO categories.

These male narratives would appear to suggest that conception, gestation, and birth could, for some men, catalyze their own perinatal psyche in a spiritual emergency, which is reported to have a neardeath component (Bache, 2000; Bragdon, 1988; Grof and Grof, 1980, 1989). It is possible, then, that their own perinatal memories, which, according to Grof and Bache, are linked with collective representations 
of birth, death, and rebirth, can be activated when they participate in procreation and become fathers. Then, by force of their dynamism, these energies find their way into world through the spontaneous ritual-making activity and "religious" encounters that Gregory Bateson called "self-initiation" (1972, p. 328; see also Peters, 1996, 1994). Bateson believed that such instances were not conventionally pathological but "trans-contextual" experiences (1972, p. 272), meaning that they could also be artistic and performative but had transcended any one context.

I do not mean here to minimize nor aggrandize psychopathology, but these anomalous male experiences could be read as primal responses to participation in the reproductive cycle. These primal responses may generate autonomic symbolic processes, potentially replay the father's own perinatal matrices, and include a symbolic or real encounter with death, with the potential for participatory and transpersonal disclosures, and, when full-blown, an "endogenous rite of passage" that does not have exogenous social support and validating belief systems (Bateson, 1961, cited in Peters, 1994, p. 6).

The appraisal of procreative men's more anomalous psychospiritual experiences viewed through perinatal contexts can legitimize their experiences in a fundamental way by placing these experiences within the greater transpersonal context. They may now be appraised against a backdrop that extends conventional psychiatric nosology to encompass spiritual emergencies, or developmental crises subsumed in a larger transpersonal developmental orientation.

\section{Midwives in Hyperspace}

I will turn now to another interesting parallel, which, while potentially contentious, is pertinent: traditional or indigenous midwifery techniques found in the anthropological record (Bates and Turner, 2003; Cosminsky, 1982; Kitzinger, 1982; Laderman, 1983; Lewis, 2003; McClain, 1989; Paul and Paul, 1975; Potter, 1974; Sered, 1994; Taussig, 1992). Many of these examples have transpersonal features in them, which I believe have a bearing on my informants' stories. Indeed, I would argue that NDEs found among ancient midwifery parallel the crises experienced by my informants around pregnancy. I will use this discussion to introduce my last informant's extraordinary narrative and to connect NDEs, pregnancy, and shamanistic midwifery. 
I began this article by saying that women's birthgiving has been related in various ways to the NDE, and that Ring has described one woman's NDE in childbirth as a shamanic initiation. I would like to develop his theme from a midwife-as-shaman perspective. It is the business of the shaman to enter and exit transpersonal alterity-scapes while in ecstatic trance or shamanic flight, thought by the locals to be concomitant with the worlds of death. Michael Harner has also noted the overlap between spiritual practice and death:

The shaman's journey starts with an experience of going through a tunnel of some kind, usually with a light at the end, and this is very similar to descriptions of the so-called near-death experiences. But the shaman goes all the way through the tunnel and explores me world that people feel themselves passing into at the time of death. (Harner, 1987, pp. 5-6)

What is perhaps less well known is the profound and complex relationship between female midwife/shamans, birth, death, and alterityscapes found in many cultures. Midwives too can fly into hyperspace in the service of birth-giving women (Paul and Paul, 1975; Potter, 1974). In some cultures such visionary states are seen as evidence of "divine election" of a midwife, the "wandering of the future practitioner's spirit into the realm of the supernatural" (Paul and Paul, 1975, p. 712). Such transpersonal visions assume a form of divine "authoritative knowledge" that ameliorates the fears of the birth-giving mother.

Lois and Benjamin Paul (1975) showed examples of what Mircea Eliade (1964) called the "ecstatic journey" among neophyte Guatemalan midwives:

Once she was walking along a path to the neighboring village.... She suddenly found herself in a huge carpeted chamber inside the hill. On a dais sat a number of deceased midwives completely white from head to toe. (Paul and Paul, 1975, p. 712)

The deceased midwives then instructed her on the ethics and morality required for her practice. This is not dissimilar to my Maori informant's experience described above.

Initiation-like experiences can come through the encounter with death in the psychic and biological "dismemberment" of labor, which opens a culturally imagined alterity-scape to them and where they establish psychic connections with ancestor spirits during their abortive or near-abortive reproductive crises. An example of this kind of phenomenon was noted by Carol Laderman, who wrote that Malaysian women in "the last extremities" of childbirth can be assisted by 
beneficent "supernatural presences" known as the "Seven Celestial Midwives" (Laderman, 1983, p. 132). She wrote of a woman in labor for days alone when

Suddenly seven beautiful smiling ladies descended from the sky. They eased her pain, delivered her baby, and washed the mother and child. When they had finished, they ascended once more to kayangan (etymologically) Siva's heaven. (Laderman, 1983, p. 132)

Women's birthing here is a cosmological event linking her labor to a Hindu heaven. Inasmuch as contact with "heaven" is generally reserved for the deceased, her childbirth experiences appeared to be related to the afterlife. Importantly, it was most frequently the death of a child that initiated women into their careers as midwives, ritual specialists, or shamans. The "possession sickness" observed by Youngsook Harvey (1980) among Korean female shamans began with a series of stillbirths; Paul and Paul (1975) described similar patterns among Guatemalan midwives. Jack Potter wrote that three Cantonese shamans (mann seag phox) began their careers after the deaths of up to six children:

In each case the woman became a shaman only after a severe crisis the death of several children, of her husband, or both. After her traumatic loss, each of the women was visited in her dreams by her children's spirits, who urged her to become a shaman. [Deceased children, who mediate between their mother and the supernatural world, are essential to the career as a spirit medium.] ... Usually the struggle between the unwilling woman and her insistent children goes on for some time. As the pressure on the woman increases, she suffers attacks of seeming madness, during which she jumps around the house, leaps on top of tables, answers questions nonsensically, and so on. Finally the reluctant candidate appears to die, and she must choose between becoming a spirit medium and dying permanently. (Potter, 1974, p. 226)

Ioan Lewis, following the classic work by Sergei Shirokogoroff (1935), has asserted that the shaman's career begins with an unsolicited, unpredictable, and uncontrolled "initial traumatic experience" (Lewis, 1986 , p. 88). Shirokogoroff called this uncontrolled possession state a psychosis that eventually had to be "mastered" (Shirokogoroff, 1935, p. 366). For Lewis, this initial traumatic connection with a spirit world then evolves into the capacity for intentional "mystical flight and other 'out of body experiences"' (Lewis, 1986, p. 88).

Therefore, we can say that what starts out as a birth-giving crisis, such as loss of a child, near-death, dissociation, or intense pain, can 
include a recapitulation of a woman's own birth trauma, which can approximate an NDE, or the "shamanic crisis" (see also Grof, 1977, 1998). The chaotic "shamanic crisis" is then honed over time into a therapeutic maneuver that combines access to a cosmological alterityscape through spiritual flight and/or the capacity of the shaman "permanently" to incarnate her spirits (Lewis, 1986, p. 85). These ideas give further credence to Ring's alignment of mystical consciousness provoked through meditative practices with the NDE.

The following, from Potter's study of Cantonese shaman/midwives, shows the integral elegance of a culturally shaped and well-honed shamanistic complex, a condensed experience fusing actual reproduction, perinatal dynamics, "shamanistic crisis," and imaginal alterity, into beautiful symmetry, illustrating all three levels of what Grof called the holotropic mind: the biographical, the perinatal, and the transpersonal level:

She jerked spasmodically and mumbled incoherent phrases. Then she started to sing a stylized, rhythmic chant, as her familiar spirits [the souls of her own dead children] possessed her and led her soul upward, away from the phenomenal world into the heavens. Their destination was the Heavenly Flower Gardens. (Potter, 1974, p. 208)

In the Cantonese paradise there are four Heavenly Flower Gardens, which are linked to earthly women's uteri. Every living person is represented by a potted flowering plant tended by two female deities; it is they who strengthen children or allow them to die: "When a woman conceives a child, a heavenly flower is planted in one of the small gardens, and a seed is sent down from heaven into the uterus of the woman" (Potter, 1974, p. 13). The shaman flies into this culturally prescribed alterity-scape specifically to "inspect the flowers" (Potter, 1974 , p. 214), to reconnoiter the condition of her Earthly client's uterus and its reproductive potential.

Thus shaman/midwives can utilize culturally refined altered states of conscious to engage the spirit world of their ancestors: human birthing bodies fused with generative cosmic bodies. These worlds are concomitant with the posthumous landscape, a theme portrayed succinctly in the title of Alma Gottlieb's recent work, The Afterlife is Where We Come From (2004). These perspectives suggest that the realm of death and the living womb somehow interpenetrate. The psychic reach of the shaman/midwife could extend into another world, the realm of the ancestors, in an effort to ensure the near-born a place in the touchable world. 


\section{Slipping into the Great Mother}

There is also a widespread pattern to consider of male ritual and trance specialists (shamans) engaging in the crises of obstructed birthing. These practices have been reported in many cultures on all continents from India to the Middle East, Australia to South America, Africa to Siberia; they are found in Malaysia, Indonesia, the Philippines, and New Zealand. Laderman described the magical reproductive maneuvers of the Cuna Indians of Panama, originally made famous by Claude Lévi-Strauss (1963) in his analysis of a chant sung by a male Cuna shaman to a woman dangerously obstructed in birthing:

The laboring woman is sick because $\mathrm{Mu}$, the power that forms the fetus, has captured her soul. The shaman must send his own soul into the spirit-world to wrest the sick woman's soul from $\mathrm{Mu}$ and her daughters. The battleground is neither in the sky nor in some invisible dimension, but within the pregnant woman's uterus, a world peopled with threatening animals and powerful spirits. Thus, in the Cuna song, the macrocosm has become the microcosm, the unseen universe is contained within a woman's genitals. (Laderman, 1983, p. 145)

However, according to Taussig, the shaman does not actually enter the woman's body or womb at all, but instead enters a mimetic copy, a spirit-double of her body $(1993$, p. 120). The shaman enters the womb of the woman's spirit-double to work on the copy, thereby affecting the human body (1993, p. 121). In fact, Taussig wrote that there is yet a further set of mimetics simultaneously operating in Cuna cosmology: that of the Great Mother and the woman's spirit body fused with her Earthly body. He cited Norman Macpherson Chapin that "during pregnancy a woman's soul or spirit body is one with the cosmos itself" (Taussig, 1993, p. 121). This also gives the impression of layered spirit worlds, and is reminiscent of the three bodies or sheaths (koshas) of Vedantic lore (causal body, subtle body, and gross body) sometimes described as onion rings (Wilber, 1998), or perhaps the Buddhist Dharmakaya, Sambhogakaya, and Nirmanakaya.

As Taussig put it, "the womb is of importance not merely for reproduction but also for the transformation of the level of reality that the chant evokes" (1993, p. 123). The womb, Taussig wrote, "is the switchboard of the male magician's reality-control apparatus" (1993, p. 123). The spiritual landscape alters suddenly and we find ourselves lost, he wrote, in a transgressive moment that creates "mimetic 
slippage" through the "gates of repression of the secretly familiar, the origin of the world, the home of all homes, the (great) mother's genitals" (1993, p. 122), thereby precipitating a metamorphosis of reality (1993, p. 126).

The instability of consciousness, the "sudden alteration in the plane of reality of the referent occurs precisely at the moment of the evocation of the womb" $(1993$, p. 123). The womb can be seen as the gateway to transpersonal consciousness and alterity-scapes, which are in effect imaginal womb worlds, spirit simulacra, or luminous body cosmologies, heavens that are ontological realities in themselves.

\section{Buddha's Luminous Womb}

A similar and perhaps more familiar cultural motif of the male "spiritual midwife" doing business with a cosmic womb is found in Tibetan Buddhist Lamaism. Tibetan cosmology, because it specifically links its consciousness practices to the afterlife and reincarnation, has been a religious tradition of great interest to both transpersonal psychologists and near-death researchers (Bache, 2000; Carr, 1993; Grof, 1998).

According to the Bardo Thodol or the Tibetan Book of the Dead (Evans-Wentz, 1960), meditation practice reaches its experiential zenith in the experience of the Dharmakaya (primary clear light) also known as Tathagatagharba, which is translated variously as Buddha Mind, Buddha Womb, and Buddha Embryo (Gross, 1994, pp. 186189), which can equate to the posthumous condition, even if achieved in life (Carr, 1993; Tambiah, 1970).

Bache, who has explored the perinatal relationship with NDEs in some experiential depth, wrote that "Vajrayana Buddhism provides us with a striking example of a spiritual tradition choosing metaphors of the womb to describe the inner textures of spiritual awakening" (2000, p. 293). He then asked the question:

Is calling enlightenment the "Buddha-womb" or the "womb of the mother consort" devoid of psychological significance? Doesn't the choice of these powerful images reflect the perception that a deep, natural (and nonreductionistic) connection exists between birth and spiritual awakening? (Bache, 2000, p. 294)

I think that it does, but it also strongly affirms our present investigation into the relationship between NDEs, shamanic crisis, 
body cosmologies, and shamanistic midwifery. Here I will draw attention to some patterns in Cuna and Cantonese midwifery similar to those of Tibetan Lamaism, a hybrid of indigenous Bon shamanism and Indian Buddhism. As noted above, in many cultures, the shaman figure begins his or her career with an initiatory crisis. The shaman, having survived death by accident and initiation, has explored the demonic underworld realm and the sky-world and learned from the experience the cause and cure of illness. Demonic hosts set upon the Buddha himself just before his enlightenment, and this constitutive enactment is reiterated in ritual throughout the Buddhist world (Kapferer, 1989). Halifax observed that "shamanic motifs, such as dismemberment, being devoured by demons, supernatural ascents and flights" are commonly found in the practice of Tibetan Lamaism (1982, p. 37), and that shamanistic crises have a relationship to biological birth $(1979$, p. 75$)$.

Indo-Tibetan cosmology comes fully laden with both intrauterine and death imagery. Indeed, some Tibetan texts (sGam.po.pa, 1971/ 12th century, pp. 63-66) elaborated in great detail the challenges of prenatal development and birth (Grof, 1998, p. 92; see also Gross, 1990 , p. 83, for a feminist perspective). Charles Laughlin, a Buddhist monk for seven years, demonstrated how perinatal experience, related to shamanism and NDEs, can arise in Vajrayana practices:

It has not yet been generally recognized [that] the experience of the womb and birth scenes spontaneously arise during meditation, particularly when the meditation is carried out in an intense retreat situation. The author recalls once meditating on the breath (anapanasati) in a straight-backed chair when a tunnel arose in the visual field at the end of which was a light which grew brighter and more intense (accompanied by a flow of energy in his body). When the climax of the experience had passed, he found himself lying on the floor in a fetal position with arms and legs twitching and in a state of confusion. (Laughlin, 1990, p. 156)

In Tibetan cosmology, birth is located as one of the six intermediate states or bardos that exist after death and before rebirth (Evan-Wentz, 1960; but see Carr, 1993). The lama works magically to "midwife" the recently-deceased-but-now-incarnating person into a birth among benevolent parents. The deceased has entered the "door of the womb," located in alterity, after being drawn toward his or her copulating parents, and thus has taken rebirth (Campbell, 1990, pp. 175-179; Evans-Wentz 1960). 
Here again we see an interpenetrating amalgam of perinatal memory, shamanic crisis, and spirit-wombs. This may well suggest that the highly refined consciousness-expanding practices of Tibetan Buddhist Lamaism reflect yet another cultural expression of the psychic amalgam found in the Cantonese and Cuna examples, which condense perinatal traumata, shamanistic crisis, and the NDE into their sacred mind-worlds. Compare, for example, the similarities between the following statements, the first from Taussig's study of Cuna shamanism and the second from Anna Klein's study of the Great Bliss Queen in the Tibetan/Bonpo tradition:

The mother's vagina was transformed into a golden tunnel through which the genipa people would travel when called by the medicine men, and her breath became a golden wind to speed them on their canoes made from the lips of her vagina. (Taussig, 1993 , p. 113)

The womb expresses the ultimate spiritual discovery. ... In Buddhist traditions, for example, the womb "expanse of reality" is a ubiquitous matrix, participating in and pervading all that is born from it. (Klein, 1995, p. 178)

In these transformed perspectives, the world is a luminous womb continuous with women's bodies. I have already shown how, in the Cuna Indian example, the woman's body is sheathed by several "Other" luminous spirit bodies, and in the Cantonese version the female uterus extends all the way to Paradise. In the Malay version, Paradise also extends to the womb. Shamans in all three examples, with some cultural variation, utilize nonordinary states of consciousness that suggest a system of midwifery that has compressed a woman's adult trauma (traumatic birth-giving and child mortality) with her own traumatic perinatal memories, and transpersonal spirit worlds into their culture-specific variations. Again, Grof's perinatal transpersonalism overlaps, in a similar way, all three levels and suggests that these "levels" coexist in a complex condition of interpenetration.

\section{A Zygotic Alterity}

At this juncture I would like to present my third story of a father and his brush with alterity. The following is from a narrative recounted by Kevin, a 25-year-old man of European descent. This event occurred soon after his child's conception, when he was 19 years old. 
I gathered from the interview that he had sensitivity to spiritual phenomena. He said that he knew from what "people had said that a woman in labor can experience hallucinations, altered states, and spiritual emergencies," and he told me that he and his girlfriend had been experimenting with sexual yoga around the time of their becoming pregnant and that they had "experimented" with psychedelic substances in the past. He said he had the experience of his child "coming down" into his partner's body during sex. He referred to birth as "pure magic," but he was troubled by the "weirdness" of reproduction:

Interviewer: Were you aware of any kind of religious, spiritual, transcendental things around birth?

Kevin: Oh, yeah! I had lots of goings on inside of me that I did not know how to talk to Rosie about. I sort of felt like I was having my own pregnancy in a way; sort of whole changes happening inside of me, of how I would relate to the world, and having my own theories about what it means to have a child. [Long pause.] When Mali was a tiny fetus I had this vision that a new universe was being born.

Interviewer: Really? When she was really tiny; how beautiful.

Kevin: It screwed with my mind.

Interviewer: Were you "out of it" ["stoned"]?

Kevin: No.

Interviewer: Dreaming?

Kevin: No.

Interviewer: It was a vision?

Kevin: Yeah. I guess I felt like I knew that it must be a whole new universe. It was like I was walking around inside of her.

Interviewer: [Hesitantly] So ... the world had become Mali?

Kevin: Yeah. I was like inside Mali and everybody had become Mali. ... Then I had this really weird death experience. We had been working building and we were having a cigarette at the end of the day and some guy came up from next door and to me he was another version of my daughter and I freaked out and blacked out. I fainted. I thought I was dying. But I remember just before that happened the light of the sun changed slightly. It was like a hallucination; looking around, 
everything was slightly different, people became superimposed on their image, it wasn't like a real image anymore, it changed slightly. Very unsettling. ... I did not know what was going on. [Laughs]. That threw me. ... After that I had a whole series of episodes around life, death, and birth. I eventually was hospitalized for psychosis. But it doesn't really matter to me what others have said; that was the most sacred experience I have ever had.

In Kevin's own words, a "whole new universe," an idiosyncratic alterity-scape, was secretly born. With a trick of the light the geography of consciousness became unstable and he oscillated between worlds, as an imaginal world began to superimpose its image onto the "ordinary" one. Furthermore, he did not quite identify with the child in the womb, but entered the mother's womb and his daughter's fetal body. He was now sheathed within the body of the unborn, sheathed by the mother, where he sat pregnant with images. And suddenly the whole phenomenal world changed and became the body of his unborn child, in whose body he now wandered alongside other versions of his unborn daughter. A hatchling spiritual landscape had wobbled into imaginal existence, a "vision" catalyzed, in my informant's words, by pregnancy.

\section{Conclusion}

Clearly these three fathers have experienced spiritual emergencies with NDE, UFO, and shamanic properties. "Shamanism," as a Western category, appears to be wed closely to NDEs. However, if we are going to compare the "deep structure" of shamanistic crisis with NDEs, then we should also consider "women's business" in this regard. We must also explore shamanism and its functions against its wider cosmic, ritual, and gendered landscapes. Furthermore, bringing the culturally submerged transpersonal states of fatherhood and male procreativity into the picture as a category of transpersonal psychology and near-death research could have interesting implications for both disciplines. In particular, this research could contribute to the arena of transpersonal developmental schemas and the controversies between Grof and Ken Wilber or Michael Washburn and Wilber (Bache, 2000, pp. 287-294; Rothberg and Kelly, 1998). The untidy 
amalgam of birth, sex, and death, and the interpenetrative nature of these phenomena, suggest remarkable similarities to Grof's observations $(1985,1998)$.

These men's stories have raised many questions, and call for more research and a further exploration of NDEs or NDE-like experiences generated around birthing. What is it that catalyzes this kind of experience in some fathers and not others? Are they environmentally mediated, or beyond culture - if there is such a thing? Can they be weighed in terms of intensity; and should they be? Are these experiences isolated events or are there more of them out there? Are they the first peel of the onion or the last? Are they a complete structure or part of a greater unfolding system? Are they "regressions" to archaic levels of the psyche, psychotic reactions, or healing events in the species mind (Bache, 2000)? Are these experiences shamanic near-death events or something else?

Questions aside, there is still, I would argue, an intriguing relationship between birth and death observed in Cuna, Tibetan, Cantonese, Malay, and Guatemalan spiritual midwifery practices that, in a fledgling way, some of my participants' experiences seemed to parallel, and this is significant. Perhaps in a more transpersonally sophisticated world, one with adequate cultural and linguistic niches to welcome, hold generously, and pile reflection and artistic rendition upon these moments, these experiences could be recognized as a form of "initiation." Such potentially dangerous but transformative NDElike moments could, with the right exogenous support, be honed into a fruitful transpersonal practice, performed to garner spiritual strength and transpersonal authority to face the oncoming developments of birth. This idea is central to shamanism: that the near-death experience can become the psychospiritual locus from which a shaman begins his or her career.

These mystical experiences, as I have shown, are profoundly related to psychosocially-constructed origin mythologies; and the vast array of origin mythologies specifically relate birth and death to cosmic bodies such as Buddha's womb. If we are not researching the other side of life when we peer into the NDE, then we are perhaps researching the farthest reaches of consciousness: alterity-scapes and their socially imaged spaces. This research would suggest that the study of enlightenment-as-alterity and its deep but largely hidden relationship to birth-giving, perinatal traumas, ecstasies, NDEs, and shamanism calls at least for further inquiry. 


\section{References}

Appadurai, A. (1996). Modernity at large: Cultural dimensions of globalization. Minneapolis, MN: University of Minnesota Press.

Alpers, A. (1985). Maori myths and tribal legends. Auckland, New Zealand: Longman Paul.

Armstrong, K. (1991). Muhammad: A biography of the Prophet. Guernsey, England: Guernsey Press.

Bache, C. (1996). Expanding Grof's concept of the perinatal: Deepening the inquiry into frightening near-death experiences. Journal of Near-Death Studies, 15, 115-139.

Bache, C. (2000). Dark night, early dawn: Steps to a deep ecology of mind. Albany, NY: State University of New York Press.

Bates, B., and Turner, A. (2003). Imagery and symbolism in the birth practices of traditional cultures. In Dundes, L. (ed.), The manner born: Birth rites in cross-cultural perspective (pp. 87-97). Walnut Creek, CA: Altimira Press.

Bateson, G. (1961). Perceval's narrative: A patient's account of his psychosis, 1830-1832. Stanford, CA: Stanford University Press.

Bateson, G. (1972). Steps to an ecology of mind. Northvale, NJ: Jason Aronson.

Best, E. (1982). Maori religion and mythology. Part 2. Te Papa Tongarewa, New Zealand: Museum of New Zealand.

Bragdon, E. (1988). A source book for helping people in spiritual emergency. Los Angeles, CA: Lightening Up Press.

Campbell. J. (1990). Transformations of myth through time. New York, NY: Harper and Row.

Carr, C. (1993). Death and near-death: A comparison of Tibetan and Euro-American experiences. Journal of Transpersonal Psychology, 25, 59-110.

Chapin, N. M. (1983). Curing among the San Blas Kuna of Panama. Unpublished doctoral dissertation, University of Arizona, Tucson, AZ.

Corbin, H. (1969). Creative imagination in the Sufism of Ibn 'Arabi (Manheim, R., trans.). Princeton, NJ: Princeton University Press.

Corbin, H. (1976). Mundus imaginalis, or the imaginal and the imaginary. Ipswich, England: Golgonooza Press.

Cosminsky, S. (1982). Childbirth and change: A Guatemalan study. In MacCormack, C. P. (ed.), Ethnography of fertility and birth (pp. 205-229). New York, NY: Academic Press.

Eliade, M. (1964). Shamanism: Archaic techniques of ecstacy (Trash, W. R., trans.). Princeton, NJ: Princeton University Press.

Evans-Wentz, W. Y. (ed.). (1960). The Tibetan book of the dead. London, England: Oxford University Press.

Ferrer, J. (2002). Revisioning transpersonal theory: A participatory vision of human spirituality. Albany, NY: State University of New York Press.

Gottlieb, A. (2004). The afterlife is where we come from: The culture of infancy in West Africa. Chicago, IL: University of Chicago Press.

Greyson, B., and Bush, N. E. (1992). Distressing near-death experiences. Psychiatry, $55,95-110$.

Grof, S. (1975). Realms of the human unconscious: Observations of LSD psychotherapy. London, England: Souvenir Press.

Grof, S. (1977). The implications of psychedelic research for anthropology: Observations from LSD psychotherapy. In Lewis, I. M. (ed.), Symbols and sentiments: Cross-cultural studies in symbolism (pp. 141-173). London, England: Academic Press.

Grof, S. (1980). LSD psychotherapy. Pomona, CA: Hunter House.

Grof, S. (1985). Beyond the brain: Birth, death and transcendence in psychotherapy. Albany, NY: State University of New York Press. 
Grof, S. (1988). The adventure of self discovery. Albany, NY: State University of New York Press.

Grof, S. (1994). Books of the dead: Manuals for living and dying. London, England: Thames and Hudson.

Grof, S. (1998). Ken Wilber's spectrum psychology: Observations from clinical consciousness research. In Rothberg, D., and Kelly, S. (eds.), Ken Wilber in dialogue: Conversations with leading transpersonal thinkers (pp. 85-116). Wheaton, IL: Quest Books.

Grof, S., and Grof, C. (1980). Beyond death: The gates of consciousness. London, England: Thames and Hudson.

Grof, S., and Grof, C. (eds.). (1989). Spiritual emergency: When personal transformation becomes a crisis. Los Angeles, CA: Tarcher.

Grof, S., and Halifax, J. (1977). The human encounter with death. New York, NY: Dutton.

Gross, R. (1994). Buddhism after patriarchy: A feminist history, analysis, and reconstruction of Buddhism. Albany, NY: State University of New York Press.

Grosso, M. (1985). The final choice: Playing the survival game. Walpole, NH: Stillpoint Press.

Halifax, J. (1979). Shamanic voices: A survey of visionary narratives. New York, NY: Dutton.

Halifax, J. (1982). Shaman: The wounded healer. London, England: Thames and Hudson.

Harner, M. (1987). The ancient wisdom in shamanic cultures. In Nicholson, S. (ed.), Shamanism: An expanded view of reality (pp. 3-16). Wheaton, IL: Theosophical Publishing House.

Harvey, Y. K. (1980). Possession sickness and women shamans in Korea. In Falk, N. A., and Gross, R. M. (eds.), Unspoken worlds: Women's religious lives in non-Western cultures (pp. 41-52). San Francisco, CA: Harper and Row.

Heggenhougen, H. K. (1980). Father and childbirth: An anthropological perspective. Journal of Nurse-Midwifery, 25(6), 21-26.

Henare, M. (2001). Tapu, mana, mauri, hua, wairua: A Mäori philosophy of vitalism and cosmos. In Grim, J. A. (ed.), Indigenous traditions and ecology: The interbeing of cosmology and community (pp. 197-221). Cambridge, MA: Harvard University Press.

Heron, J. (1998). Sacred science: Person-centered inquiry into the spiritual and the subtle. Ross-on-Wye, England: PCCS Books.

Hillman, J. (1975). Re-visioning psychology. New York, NY: Harper and Row.

Kapferer, B. (1989). Performance and the structuring of meaning and experience. In Turner, V. W., and Bruner, E. M. (eds.), The anthropology of experience (pp. 188-203). Urbana, IL: University of Illinois Press.

Katz, S. T. (1978). Language, espistemology, and mysticism. In Katz, S. T. (ed.), Mysticism and philosophical analysis (pp. 22-74). London, England: Sheldon Press.

Kitzinger, S. (1982). The social context of birth: Some comparisons between childbirth in Jamaica and Britain. In MacCormack, C. P. (ed.), Ethnography of fertility and birth (pp. 181-203). London, England: Academic Press.

Klein, A. (1995). Meeting the great bliss queen: Buddhists, feminists, and the art of the self. Boston, MA: Beacon Press.

Kuper, A. (1994). Culture, identity and the project of a cosmopolitan anthropology. Man, 29, 537-554.

Laderman, C. (1983). Wives and midwives: Childbirth and nutrition in rural Malaysia. Berkeley, CA: University of California Press.

Lahood, G. (2006). Bearing in mind: Birth, fathers, ritual and reproductive consciousness in transpersonal anthropological perspective. Unpublished doctoral dissertation, Massey University, Auckland, New Zealand. 
Laughlin, C. (1988). Transpersonal anthropology: Some methodological issues. Western Canadian Anthropology, 5, 29-60.

Laughlin, C. (1990). Womb = woman = world: Gender and transcendence in Tibetan tantric Buddhism. Pre- and Perinatal Psychology, 5, 147-165.

Laughlin, C. (1994). Psychic energy and transpersonal experience: A biogenetic structural account of the Tibetan dumo yoga practice. In Young, D., and Goulet, J. (eds.) Being changed by cross-cultural encounters: The anthropology of extraordinary experience (pp 99-134). Peterborough, Ontario: Broadview Press.

Lawson, A. (1987). Perinatal imagery in UFO abduction reports. In Verny, T. (ed.), Preand perinatal psychology: An introduction (pp. 260-291). New York, NY: Human Sciences Press.

Lévy-Strauss, C. (1963). Structural anthropology. New York, NY: Basic Books.

Lewis. I. M. (1986). Religion in context: Cults and charisma. Cambridge, England: Cambridge University Press.

Lewis, I. M. (2003). Trance, possession, shamanism and sex. Anthropology of Consciousness, $14,20-39$.

McClain, C. S. (1989). Reinterpreting women in healing roles. In McClain, C. S. (ed.), Women as healers: Cross-cultural perspectives (pp. 1-19). New Brunswick, NJ: Rutgers University Press.

McKenna, T. (1982). New and old maps of hyper-space [Audio cassette]. Big Sur, CA: Dolphin Tapes.

Paul, L., and Paul, B. D. (1975). The Maya midwife as sacred specialist: A Guatemalan case. American Ethnologist, 2, 707-726.

Peters, L. G. (1994). Rites of passage and the borderline syndrome: Perspectives in transpersonal anthropology. Anthropology of Consciousness, 5, 1-15.

Peters, L. G. (1996). The contribution of anthropology to transpersonal psychiatry. In Scotton, B. W., Chinen, A. B., and Battista, J. R. (eds.), Textbook of transpersonal psychiatry and psychology (pp. 207-216). New York, NY: Basic Books.

Potter, J. M. (1974). Cantonese shamanism. In Wolf, A. P. (ed.), Religion and ritual in Chinese society (pp. 207-231). Stanford, CA: Stanford University Press.

Priya, J. (1992). Birth traditions and modern pregnancy care. Dorset, England: Element.

Rice, A. (1976). Interview with the vampire. New York, NY: Knopf.

Richman, J. (1982). Men's experiences of pregnancy and childbirth. In McKee, L., and O'Brien, M. (eds.), The father figure (pp. 89-103). New York, NY: Tavistock.

Ring, $K$. (1976). Mapping the regions of consciousness: A conceptual reformulation. Journal of Transpersonal Psychology, 8, 77-99.

Ring, K. (1989). Near-death experiences and UFO encounters as shamanic initiations: Some conceptual and evolutionary implications. ReVision, 11(3), 14-22.

Ring, K. (1990). Shamanic initiation, imaginal worlds, and light after death. In Doore, G. (ed.), What survives? Contemporary explorations of life after death (pp. 204-215.) Los Angeles, CA: Tarcher.

Rothberg, D., and Kelly, S. (eds.), Ken Wilber in dialogue: Conversations with leading transpersonal thinkers. Wheaton, IL: Quest Books.

Sered, S. (1994). Priestess, mother, sacred sister: Religions dominated by women. New York, NY: Oxford University Press.

sGam.po.pa. (1971). Jewel ornament of liberation (Guenther, H. V., trans.). Berkeley, CA: Shambhala. (Original work published $12^{\text {th }}$ century)

Shirokogoroff, S. (1935). Psychomental complex of the Tungus. London, England: Routledge and Kegan Paul.

Stanner, W. E. H. (1956). The dreaming. In Hungerford, T. A. G. (ed.), Australian signpost: An anthology (pp. 51-65). Melbourne, Australia: F. W. Cheshire.

Tambiah, S. (1970). Buddhism and spirit cults in north-east Thailand. Cambridge, England: Cambridge University Press. 
Tambiah, S. (1990). Magic, science, religion, and the scope of rationality. Cambridge, England: Cambridge University Press.

Tarnas, R. (1991). The passion of the Western mind: Understanding the ideas that have shaped our worldview. New York, NY: Harmony Books.

Taussig, M. (1993). Mimesis and alterity: A particular history of the senses. New York, NY: Routledge.

Thompson, K. (1989). The UFO encounter experience as a crisis of transformation. In Grof., S., and Grof, C. (eds.), Spiritual emergency: When personal transformation becomes a crisis (pp. 121-134). Los Angeles, CA: Tarcher.

Tylor, E. B. (1878). Researches into the early history of mankind and the development of civilization. London, England: John Murray.

Walsh, R. (1995). Phenomenological mapping: A method for describing and comparing states of consciousness. Journal of Transpersonal Psychology, 27, 25-57.

Wilber, K. (1998). The eye of spirit: An integral vision for a world gone slightly mad. Boston, MA: Shambhala.

Young, D., and Goulet, J. (eds.). (1994). Being changed by cross-cultural encounters. Peterborough, Ontario: Broadview Press. 